\title{
PENGARUH PERSEPSI KEGUNAAN, PERSEPSI KEUNTUNGAN, PERSEPSI KEAMANAN TERHADAP MINAT NASABAH BNI MENGGUNAKAN MOBILE BANKING
}

\author{
Jefri Wandi \\ Syamsul Bachri \\ Benyamin Parubak \\ Program Studi S1 Jurusan Manajemen Fakultas Ekonomi dan Bisnis, Universitas Tadulako \\ Email:jefriwandi02@gmail.com;syamsulbahri09@gmail.com;benyaminparubak11@gmail.com
}

\begin{abstract}
The objective of this research is to analyze the effect of usability, profit, security simultaneously and partially on customer interest of BNI in using mobile banking at BNI Palu branch. It was a quantitative research used multiple linear regression analysis method with a total of 100 respondents. The results of this researchshow thatusability, profit and security perceptions simultaneously have a significant effect on customer interest of BNI in using mobile banking at BNI Palu branch. Usability perception has a significant effect on customer interest of BNI in using mobile banking at BNI Palu branch.Profit perception has a significant effect on customer interest of BNI in using mobile banking at BNI Palu branch. Security perception has a significant effect on customer interest of BNI in using mobile banking at BNI Palu branch.
\end{abstract}

Keywords:Usability, Profit, Security, Customer Interest, Mobile Banking

\begin{abstract}
Abstrak
Penelitian ini bertujuan untuk menganalisis pengaruh kegunaan, keuntungan, keamanan secara serempak dan parsial terhadap minat nasabah Bank BNI dalam penggunaan mobile banking pada BNI cabang Palu. Penelitian ini adalah penelitian kuantitatif dengan metode analisis regresi linier berganda dengan total responden sebanyak 100 orang. Hasil penelitian ini menunjukkan bahwapersepsi kegunaan, persepsi keuntungan dan persepsi keamanan secara serempak berpengaruh signifikan terhadap minat nasabah Bank BNI dalam menggunakan mobile banking pada BNI cabang Palu. Persepsi kegunaan mempunyai pengaruh signifikan terhadap minat nasabah Bank BNI dalam menggunaan mobile bankingpada BNI cabang Palu.Persepsi keuntungan mempunyai pengaruh signifikan terhadap minat nasabah Bank BNI dalam menggunakan mobile banking pada BNI cabang Palu. Persepsi keamanan mempunyai pengaruh signifikan terhadap minat nasabah Bank BNI dalam menggunakan mobile banking pada BNI cabang Palu.
\end{abstract}

Kata Kunci:Kegunaan, Keuntungan, Keamanan, Minat Nasabah, Mobile Banking

\section{PENDAhUluaN}

Beberapa tahun terakhir banyak sekali perusahaan yang berusaha dan berlomba untuk bisa bersaing pada pasar. Banyak perusahaan membuat inovasi baru untuk bersaing dengan perusahan lainnya. Sehingga membuat perusahaan melakukan berbagai cara agar bisa bersaing untuk memperbaiki bisnisnya. Perusahaan harus bisa melihat dan mengatasi berbagai hal untuk dapat berkembang dan memajukan perusahaannya agar tidak kalah bersaing dengan perusahaan lainnya. Seiring perkembangan lingkungan bisnis yang semakin kompetitif, peran teknologi sangat diperlukan dalam setiap aktifitas organisasi (Ellitan dan Anatan, 2015:26). Seperti halnya perbankan yang mempromosikan kebutuhan konsumen dengan berbagai fasilitas yang dapat mempermudah urusan konsumen seperti fasilitas mobile banking. 
BNI mobile banking adalah sebuah fasilitas perbankan yang digunakan nasabah untuk melakukan transaksimelalui smartphone, dengan aman, mudah, dan cepat. BNI mobile banking memberikan layanan transaksi yang dapat mengetahui informasi saldo, transfer, pembayaran listrik, PDAM, tiket pesawat, pembelian pulsa prabayar, pembukaan rekening deposito, dan lain-lain (www.bni.co.id).

Di kota-kota besar di seluruh dunia banyak perbankan yang telah meluncurkan produk mobile banking seperti di Indonesia salah satunya BNI mobile banking. Menurut laporan MEF, 80\% responden di Indonesia menyatakan telah menggunakan sarana mobile banking.

Di Indonesia mobile banking lebih efektif di perkotaan dibandingkan dengan pedesaan. Hal ini karena masyarakat perkotaan lebihfamiliardengan menggunakan bank sebagai tempat kegiatanfinancialketimbang masyarakat yang tinggal di pedesaan. Bagi masyarakat perkotaanmobile bankingmerupakan alat pengelolaan keuangan yang baik bagi orang-orang sibuk sehingga mempermudah dan mengefisienkan waktu mereka.

Bank memberikan pelayanannya sesuai dengan kebutuhan nasabahnya searah dengan perkembangan teknologi dan gaya hidup yang berkembang saat ini. Bank harus lebih bekerja keras untuk dapat memasarkan layanan yang di butuhan nasabahnya sehingga mereka berminat untuk menggunakan produk-produk yang dipasarkan oleh bank. Berbagai kemudahan yang diberikan bank kepada nasabah membuat eksistensi bank tersebut menjadi lebih terkenal dan diingat oleh nasabah. BNI mobile banking dari tahun ke tahun terus diperbaharui untuk dapat mengakses berbagai macam fitur dan tampilan yang dapat dimengerti dan membantu nasabah seperti informasi saldo dan melakukan pembayaran dengan cukup satu aplikasi.

Berbagai macam fitur yang disediakan dalam satu aplikasi serta banyak keuntungan yang akan di dapatkan nasabah dan bank secara langsung. Selain itu, mobile banking tidak hanya memberikan manfaat dan keuntungan bagi nasabahnya, tetapi ada juga kekurangan dari penggunaanmobile banking itu sendiri, antara lain keamanan dari mobile bakingyang harus disadari oleh pengguna mobile banking. Keamanan pada mobile banking terdapat pada perangkat HP nasabah tersebut dengan mengatur password atau pin yang digunakan untuk mengakses ketika ingin bertransaksi menggunakan mobile baking. Oleh karena itu, pin atau password yang dimiliki nasabah harus di rahasiakan agar dapat mengurangi tingkat kejahatan.

Menurut salah satu nasabah pada Bank BNI cabang Palu setelah memakai mobile banking dapat memungkinkan untuk mengirim dan menerima uang dengan menu transfer secara cepat, sehingga nasabah tidak perlu untuk datang langsung ke bank atau mengantri di mesin ATM, serta dapat memantau pengeluaran karena terdapat menu mutasi rekening nasabah. Keuntungan bagi pengguna mobile banking dapat mengefisienkan waktu bagi nasabah dan perbankan karena fasilitas yang dapat memudahkan nasabah ketika bertransaksi. Perbankan dapat meningkatkan kepuasan nasabah tanpa perlu melihat jarak dan waktu perbankan dengan mudah menjangkau nasabah dengan adanya mobile banking yang dimiliki nasabah tersebut.

\section{KAJIAN LITERATUR DAN KERANGKA PEMIKIRAN}

Pengertian pemasaran menurut Stanton (2001:7) adalah suatu sistem keseluruhan dari kegiatankegiatan bisnis yang ditujukan untuk merencanakan, menentukan harga, mempromosikan dan mendistribusikan barang dan jasa yang memuaskan kebutuhan baik kepada pembeli yang ada maupun pembeli potensial. Menurut Kotler (2001) definisi pemasaran adalah bekerja dengan pasar sasaran untuk mewujudkan pertukaran yang potensial dengan maksud memuaskan kebutuhan dan keinginan manusia. Proses pemasaran membutuhkan kemampuan untuk bekerja dan keterampilan bagaimana cara kita menjual agar produk seperti barang atau jasa yang akan di pasarkan bisa tepat sasaran sehingga di terima dan diminati oleh kalangan masyarakat. Oleh karena itu, manajemen pemasaran harus bisa mengetahui apa yang dibutuhkan dan diminati masyarakat sehingga dapat unggul dalam 
mengait masyarakat dengan berbagai strategi pemasaran yang dibuat sehingga perusahaan harus mampu menciptakan suatu produk yang unggul.

Perilaku konsumen setiap manusia yang satu dan lainnya pasti berbeda-beda karena mereka menyesuaikan dengan perkembangan tempat tinggal mereka. Perusahaan hampir selalu ada dalam setiap kegiatan manusia, karena perusahaan selalu menciptakan sesuatu yang diperlukan oleh manusia. Sehingga perusahaan juga harus selalu bisa menyesuaikan dengan lingkungan dan perkembangan zaman.

Menurut Kotler dan Keller (2009:166) perilaku konsumen adalah studi tentang bagaimana individu, kelompok, dan organisasi memilih, membeli, menggunakan dan bagaimana barang, jasa, ide atau pengalaman untuk memuaskan kebutuhan dan keinginan mereka. Setiap individu biasanya mempunyai pertimbangan dalam memutuskan sesuatu ketika melakukan transaksi pembelian pada suatu produk. Ada beberapa faktor yang menentukan perilaku konsumen antara lain harga, kualitas produk, kegunaan, dan kesukaan. Dimana pembeli memutuskan untuk membeli tergantung yang mereka butuhkan baik dilihat dari harga barang tersebut mahal ataupun murah, kualitas ataupun melihat merek dari produk tersebut, kegunaan atau menurut yang mereka sukai.

Pengertian minat menurut Slameto (2010:180) mengatakan bahwa minat adalah kecenderungan yang menetap untuk memperhatikan dan mengenang beberapa aktivitas, sehingga seseorang yang berminat terhadap aktivitas akan memperhatikan aktivitas itu secara konsisten dengan rasa senang. Menurut Ferdinand (2011:129) minat beli dapat diidentifikasi melalui dimensi yaitu minat transaksional, minat referensial, minat preferensial dan minat transaksional. Minat seseorang tidak bisa ditentukan melainkan oleh orang tersebut. Minat seseorang muncul dari keinginan untuk memiliki suatu produk berdasarkan pertimbangan yang mereka miliki. Secara umum, pengertian minat adalah keinginan seseorang dalam diri untuk bisa memiliki atau menggunakan objek tertentu. Keinginan tersebut bisa dirasakan seseorang sesuai yang mereka rasakan memberikan manfaat untuk diri mereka. Minat seseorang tidak bisa dipaksakan dan ditentukan oleh orang lain melainkan diri mereka sendiri, tetapi minat seseorang bisa diketahui orang lain dengan melihat perilaku seseorang tersebut. Oleh karena itu, perusahaan harus mampu mengetahui minat seseorang tersebut dengan membaca situasi atau perkembangan tempat tinggal mereka.

Mobile banking merupakan sarana yang diberikan kepada nasabah perbankan agar dapat melakukan transaksi melalui smartphone dengan menggunakan menu layanan yang terdapat didalam mobile banking untuk mempermudah nasabah mereka untuk melakukan transaksi. Mobile bankingmemiliki fitur yang cukup lengkap untuk bertransaksi dengan menu yang simpel dan sederhana memudahkan nasabah untuk menjalankan transaksi cukup dengan memasukan password atau pin yang sudah terdaftar maka menu aplikasi akan langsung terbuka dan selanjutnya mengikuti petunjuk yang ada didalam mobile banking.

BNI mobile banking terdapat berbagai macam fasilitas layanan perbankan sehingga nasabah tinggal memilih transaksi yang akan dilakukan seperti cek saldo, transfer, pembayaran PDAM, pembayaran listrik, pembayaran tiket pesawat, pembelian pulsa prabayar, cek mutasi, pembukaan rekening deposito, dan lain-lain (www.bni.co.id). Layanan mobile banking sangatlah mudah digunakan oleh nasabah. Nasabah cukup hanya dengan memasukan password atau pin untuk mengakses mobile banking sehingga aman digunakan. Mobile banking setiap perbankan memiliki fitur dan tampilan yag berbeda-beda dengan berbagai design yang menarik dan berbagai macam fitur yang disediakan dalam satu aplikasi. Cukup dengan melakukan beberapa langkah sesuai dengan petunjuk pada mobile banking.

Salah satu kelebihan fitur dari BNI mobile banking adalah layanan ini masih terintegrasi dengan BNI internet banking karena ketika nasabah mengakses seluruh daftar nomor rekening tujuan transfer ataupun nomor rekening tagihan yang telah tersimpan sebelumnya di internet banking, nasabah tidak 
perlu mengisi kembali daftar nomor rekening tujuan lagi. Adapun manfaat fitur-fitur BNI mobile banking seperti transfer antar rekening atau antar bank, transfer yang dapat terjadwal, pembayaran tagihanseperti tagihan listrik, PDAM, TV berlangganan, dan lain-lain, pembelian pulsa prabayar dan situs e-commerce, cek saldo dan mutasi rekening serta cek bukti transfer.

Fitur-fitur mobile banking ini sangat penting untuk diketahui nasabah sehingga menjadi alternatif yang patut untuk dicoba oleh setiap pengguna jasa perbankan. Setelah nasabah memiliki akun untuk dapat mengakses BNI mobile banking pasti banyak aktifitas perbankan yang dapat nasabah lakukan untuk membantu mereka dalam memudahkan urusannya dalam bertransaksi tanpa perlu nasabah datang langsung ke bank.

Menurut Jogiyanto (2007:14) persepsi kegunaan didefinisikan sebagai sejauh mana seseorang percaya bahwa menggunakan suatu teknologi akan meningkatkan kinerjanya. Persepsi kegunaan juga didefinisikan sebagai tingkat dimana seseorang percaya bahwa dengan menggunakan sistem tertentu akan meningkatkan kinerjanya (Davis, 1989:318). Persepsi kegunaan merupakan suatu ukuran yang menunjukkan atau menjelaskan manfaat dari sesuatu yang dirasakan ketika orang tersebut menggunakan produk berupa barang atau jasa sehingga mereka puas dengan manfaat produk tersebut. Seiring perkembangan zaman hampir seluruh dunia memiliki handphone dan masyarakat sudah bisa memiliki handphone dengan harga yang begitu terjangkau dengan fasilitas yang canggih baik dari kalangan atas maupun menengah ke bawah. Selain digunakan untuk berkomunikasi handphone juga digunakan untuk menjadi sarana alat berdagang untuk mendapatkan keuntungan. Banyak handphone sekarang ini yang memiliki basis akses internet cepat dan memiliki fitur yang canggih seperti mobile banking yang dapat diunduh pada handphone. Kegunaan menggunakan mobile banking antara lain mengetahui informasi saldo terakhir, transfer sesama bank atau bank lain, pembayaran listrik, PDAM, internet, TV berlangganan, pembelian pulsa prabayar, dan cek saldo dan mutasi.

Persepsi keuntungan merupakan sesuatu yang diperoleh setelah mencoba suatu produk dan dapat dirasakan manfaatnya oleh konsumen ketika menggunakan suatu produk barang dan jasa yang mereka gunakan. Seperti mobile banking banyak keuntungan yang diberikan kepada nasabah ketika melakukan transaksi menggunakan mobile banking. Keuntungan mobile banking antara lain nasabah dapat melakukan transaksi selama 24 jam, menggunakan mobile bankingnasabah menghemat banyak waktu, ketika melakukan transaksi hasilnya cepat diketahui, mobile banking pada smartphone sangat mudah untuk dimengerti sehingga nasabah nyaman untuk bertransaksi dan tampilan fitur dari mobile banking juga sangat simpledan mudah untuk dijalankan. Nasabah hanya perlu memasukan password atau pin dan mengikuti petunjuknya.

Persepsi keamanan adalah keadaan bebas dari bahaya. Istilah ini biasa digunakan dengan hubungan kejahatan, kecelakaan, termasuk serangan hacker atau craker dari komputer (www.wikipedia.org). Keamanan adalah hal yang sangat penting dalam sebuah sistem perbankan karena menyangkut datadata privasi penting seperti data pribadi nasabah yang sangat rahasia. Oleh karena itu, keamanan suatu aplikasi sangatlah penting bagi perbankan. Keamanan menjadi salah satu alasan yang mempengaruhi nasabah menggunakanmobile banking. Ketika seorang pengguna mobile banking memberikan password atau pin kepada hacker maka dengan mudah mereka bisa mengetahui dan melacak sistem mereka untuk membobol rekening nasabah. Serangan lain pun juga marak terjadi dengan modusmodus penipuan yang beragam. Selain itu yang harus dihadapi dalam mobile banking adalah kegagalan dalam melakukan transaksi, dan melakukan transaksi berulang karena tidak memiliki mekanisme untuk menjaga koneksi, dampaknya dapat menimbulkan kerugian pada nasabah walaupun kita bisa mengadukan kepada pihak bank dengan memakan waktu yang cukup lama. Seringkali masalah keamanan sistem aplikasi diabaikan oleh para pengguna mobile banking, justru setelah terjadi sesuatu bencana barulah disadari pentingnya pengamanan suatu aplikasi untuk tetap terjaga. 
Keamanan menggunakan mobile banking antara lain produk aman digunakan, mengurangi resiko kejahatan, merahasiakan data informasi nasabah

\section{METODE PENELITIAN}

Jenis penelitian ini merupakan penelitian deskriptif kausal. Jenis penelitian deskriptif dilakukan untuk memperoleh gambaran tentang minat nasabah dalam menggunakan mobile banking pada Bank BNI cabang Palu yang belum menggunakan mobile banking. Menurut Gay (dalam Umar 2010:21) bahwa metode riset deskriptifbertujuan untuk menjawab pertanyaan menyangkut sesuatu pada waktu berlangsungnya riset. Penelitian kausal bertujuan untuk mengetahui hubungan antara variabel penelitian melalui pengujian hipotesis yang memakai perhitungan statistik (Malhotra, 2006:291).

Populasi penelitian ini yaitu nasabah Bank BNI cabang Palu yang belum menggunakan mobile banking tetapi mengetahui tentang mobile banking. Adapun jumlah populasi nasabah Bank BNI cabang Palu yang berminat menggunakan mobile banking tidak diketahui secara pasti. Hal ini dikarenakan tidak terdapat dan tidak adanya data yang akurat mengenai jumlah nasabah Bank BNI cabang Palu yang belum menggunakan mobile banking tetapi mengetahui tentang mobile banking. Sehingga ketika peneliti bertemu dengan nasabah langsung yang berada di Bank BNI cabang Palu yang bertemu secara kebetulan, kemudian peneliti merasa cocok untuk dijadikan sampel maka nasabah tersebut diberikan kuesioner untuk diisi dan menjadi sampel untuk penelitian. Menurut Widiyanto (2008:19) apabila populasi berukuran besar dan jumlahnya tidak bisa dihitung maka digunakan rumus sebagai berikut :

$$
\begin{aligned}
n & =\frac{\mathrm{z}^{2}}{4(\text { Moe })^{2}} \\
\mathrm{n} & =\frac{1,96^{2}}{4(0,1)^{2}} \\
& =96,04
\end{aligned}
$$

Ket: $\quad \mathrm{n} \quad$ : Jumlah sampel

Z : Persentase keyakinan sampel $95 \%$

Pada penentuan ini $\mathrm{Z}$ pada $\alpha=0,5$ adalah 1,96

Moe : Margin Of Eror, yaitu tingkat kesalahan yang dapat ditoleransi, ditentukan sebesar $10 \%$

Berdasarkan rumus tersebut diatas, maka jumlah yang diteliti sebanyak 96,04 responden. Namun dalam penelitian ini untuk memudahkan peneliti menggenapkan menjadi 100 responden yang digunakan sebagai sampel.

Dalam penelitian ini digunakan skala numerik untuk membantu responden agar lebih mudah untuk mengisi pernyataan pada kuesioner yang telah diberikan. Skala ini merupakan variasi skala diferensial semantik. Skala ini juga menggunakan dua kutub esktrim, positif dan negatif, hanya pilihan yang tersedia adalah angka. Sama seperti pada diferensial semantik, jumlah angka harus ganjil, umumnya 5,7, dan 9. (Simamora, 2005:28)

Uji validitas digunakan untuk mengukur sah atau valid tidaknya suatu kuesioner (Ghozali, 2005:52). Suatu kuesioner dikatakan valid ketika pertanyaan pada kuesioner mampu untuk menjelaskan sesuatu yang akan diukur oleh kuesioner tersebut. Menurut Masrun dalam Sugiono (2009:188-189), suatu instrumen penelitian dianggap valid, jika item mempunyai korelasi positif 
dengan kriterium (skor total) serta korelasi yang tinggi, menunjukkan bahwa item tersebut mempunyai validitas yang tinggi pula. Biasanya syarat minimum untuk dianggap memenuhi syarat, jika $r \geq 0,3$. Jadi, jika korelasi antara item dengan skor total $\leq 0,3$, maka item dalam instrumen tersebut dianggap tidak valid.

Menurut Ghozali (2005:53) uji reliabilitas ialah alat yang digunakan untuk mengukur suatu kuesioner yang merupakan indikator dari variabel atau konstruk. Suatu kuesioner dikatakan reliabel ketika jawaban responden terhadap pernyataan adalah konsisten atau stabil dari waktu ke waktu. Aplikasi SPSS diberikan fasilitas untuk mengukur reliabilitas dengan uji statistik Cronbach Alpha $(\alpha)$, suatu konstruk atau variabel dikatakan reliabel jika memberikan nilai Conbarch Alpha> 0,6 (Ghozali, 2005:53).

Menurut Sunyoto (2012:49) uji normalitas bertujuan untuk menguji data variabel bebas (X) dan data variabel terikat $(\mathrm{Y})$ pada persamaan regresi yang dihasilkan, apakah berdistribusi normal atau berdistribusi tidak normal. Persamaan regresi dikatakan baik jika mempunyai data variabel bebas dan data variabel terikat berdistribusi mendekati normal atau tidak normal sama sekali.

Menurut Ghozali (2005:57) uji multikoliniearitas dapat dilihat dari nilai tolerance dan lawannyavariance inflation factor (VIF). Jadi nilai tolerance yang rendah sama dengan nilai VIF tinggi. Nilai cut off yang umum dipakai untuk menunujukkan adanya multikoliniearitas adalah nilai tolerance $\leq 0.10$ atau sama dengan nilai $\mathrm{VIF} \geq 10$.

Menurut Sunyoto (2012:50) uji heteroskedastisitas dalam persamaan regresi berganda diuji mengenai sama atau tidaknya varian dari residual dan observasi yang satu dengan observasi lain. Persamaan yang baik adalah jika tidak tejadi heteroskedastisitas.

Untuk menjawab permasalahan dan menguji hipotesis digunakan regresi linear berganda dengan rumus sebagai berikut: $Y=a+b_{1} X_{1}+b_{2} X_{2}+b_{3} X_{3}+\ldots \ldots . . e$

Sehingga untuk mengetahui seberapa besar pengaruh antara persepsi kegunaan, persepsi keuntungan, dan persepsi keamanan terhadap minat menggunakan mobile banking. Rumus yang digunakan dalam penelitian ini adalah:

$\mathrm{MP}=\mathrm{a}+\mathrm{b}_{1} \mathrm{KG}+\mathrm{b}_{2} \mathrm{KT}+\mathrm{b}_{3} \mathrm{KM}+\mathrm{e}$

Keterangan :

\begin{tabular}{|c|c|}
\hline MP & $=$ Minat menggunakanmobile banking (Dependen) \\
\hline KG & = Kegunaan (Independen) \\
\hline KT & $=$ Keuntungan (Independen) \\
\hline KM & = Keamanan (Independen) \\
\hline & $=$ Konstanta \\
\hline$b_{1}, b_{2}, b_{3}$ & $=$ Variabel independen \\
\hline
\end{tabular}

\section{HASIL DAN PEMBAHASAN}

Hasil pengolahan uji normalitas digunakan untuk mendeteksi normalitas data, model regresi yang baik adalah memiliki distribusi data normal atau mendekati normal. Hasil uji normalitas sebagai berikut:

Hasil pengolahan data uji normalitas, didapatkan nilai Asymp. Sig (2-tailed) sebesar 0,852 artinya lebih besar dari 0,05 , sehingga disimpulkan bahwa data pada penelitian ini menunjukkan bahwa data berdistribusi normal.

Dalam menjawab permasalahan dan menguji hipotesis dalam penelitian ini digunakan alat analisis statistik regresi linear berganda (Multiple linear regression) dengan menggunakan SPSS versi 16. Untuk lebih jelasnya dapat dilihat pada Tabel 1. 
Tabel 1 Rekapitulasi Hasil Uji Regresi Linear Berganda Coefficients ${ }^{\mathbf{a}}$

\begin{tabular}{|c|c|c|c|c|c|}
\hline \multirow[t]{2}{*}{ Model } & \multicolumn{2}{|c|}{$\begin{array}{c}\text { Unstandardized } \\
\text { Coefficients }\end{array}$} & $\begin{array}{c}\text { Standardized } \\
\text { Coefficients }\end{array}$ & \multirow[t]{2}{*}{$\mathrm{T}$} & \multirow[t]{2}{*}{ Sig } \\
\hline & B & Std. Error & Beta & & \\
\hline (Constant) & 13.850 & 2.658 & & 5.210 & .000 \\
\hline Kegunaan & .243 & .074 & .313 & 3.274 & .001 \\
\hline Keuntungan & .249 & .079 & .306 & 3.159 & .002 \\
\hline Keamanan & 207 & .080 & .237 & 2.588 & .011 \\
\hline & & \multirow{2}{*}{\multicolumn{2}{|c|}{$\begin{array}{l}\mathrm{F}_{\text {tabel }} \\
\mathrm{F}_{\text {bitur }}\end{array}$}} & $=2,7058$ \\
\hline \multicolumn{2}{|c|}{ R Square } & 0,547 & & & \\
\hline \multicolumn{2}{|c|}{ AdjustedSquare= } & 0,532 & & fikans & \\
\hline
\end{tabular}

Sumber: Data primer yang telah diolah

Dari hasil uji regresi yang tertera pada tabel 3 di atas, dapat diketahui bahwa persamaan regresi yang didapatkan adalah:

\section{$\mathrm{Y}=13.850+0.243 \mathrm{X}_{1}+0.249 \mathrm{X}_{2}+0.207 \mathrm{X}_{3}$}

Persamaan regresi linear berganda diatas memberikan gambaran mengenai besarnya pengaruh variabel independen $(\mathrm{X})$ yang dianalisis memberikan pengaruh positif terhadap variabel dependen $(\mathrm{Y})$ yaitu minat nasabah dalam menggunakan mobile banking pada BNI cabang Palu.

Selanjutnya penjelasan yang lebih akurat akan di jelaskan terlebih dahulu yakni:

1. Nilai konstanta sebesar 13,850 sehingga dapat diartikan apabila pengaruh kegunaan, keuntungan, dan keamanan tidak mengalami perubahan, maka minat nasabah Bank BNI dalam menggunakan mobile banking pada BNI cabang Palu sebesar 13,850.

2. Variabel kegunaan $\left(\mathrm{X}_{1}\right)$ sebesar 0,243 dapat diartikan bahwa terdapat pengaruh positif antara kegunaan dengan minat nasabah dalam menggunakan mobile banking BNI cabang Palu, atau dengan kata lain apabila pengaruh variabel kegunaan meningkat, maka minat menggunakan mobile banking juga akan naik.

3. Variabel keuntungan $\left(\mathrm{X}_{2}\right)$ sebesar 0,249 dapat diartikan bahwa terdapat pengaruh positif antara keuntungan dengan minat nasabah dalam menggunakan mobile banking BNI cabang Palu, atau dengan kata lain apabila pengaruh variabel keuntungan meningkat, maka minat menggunakan mobile banking juga akan naik.

4. Variabel keamanan $\left(\mathrm{X}_{3}\right)$ sebesar 0,207 dapat diartikan bahwa terdapat pengaruh positif antara keamanan dengan minat nasabah dalam menggunakan mobile banking BNI cabang Palu, atau dengan kata lain apabila pengaruh variabel keamanan meningkat, maka minat menggunakan mobile banking juga akan naik.

Sehingga dapat disimpulkan:

1. Hipotesesis pertama yang menyatakan pengaruh kegunaan, keuntungan, dan keamanan secara bersama-sama berpengaruh terhadap minat nasabah Bank BNI dalam menggunakan mobile banking pada BNI cabang Palu didukung.

2. Hipotesis kedua yang menyatakan "Kegunaan berpengaruh terhadap minat nasabah Bank BNI dalam menggunakan mobile banking pada BNI cabang Palu" didukung. 
3. Hipotesis ketiga yang menyatakan "Keuntungan berpengaruh terhadap minat nasabah Bank BNI dalam menggunakan mobile banking pada BNI cabang Palu" didukung.

4. Hipotesis keempat yang menyatakan "Keamanan berpengaruh terhadap minat nasabah Bank BNI dalam menggunakan mobile banking pada BNI cabang Palu" didukung.

Hasil uji determinasi diperoleh nilai koefisien korelasi (r) sebesar 0,739 dan nilai adjusted $R$ square $\left(\mathrm{R}^{2}\right)$ yng diperoleh bernilai $0,532(53,2 \%)$. Artinya terdapat pengaruh kegunaan, keutungan dan keamanan memiliki pengaruh positif dan mempengaruhi 53,2\% perubahan pada minat nasabah menggunaan mobile banking, sedangkan sisanya sebesar 46,8\% dipengaruhi oleh variabel lain di luar penelitian ini.

Berdasarkan hasil uji pada regresi linier berganda didapat nilai $\mathrm{F}$ hitung sebesar 38,580 dan nilai $\mathrm{F}$ tabel 2,7058 dengan tingkat signifikansi 0,000 . Nilai $\mathrm{F}$ hitung lebih besar dari pada nilai $\mathrm{F}$ tabel $(38,580>2,7058)$, nilai koefisien korelasi berarah positif sebesar 0,739 dan nilai signifikansi lebih kecil dari 0,05 $(0,000<0,05)$ maka dapat disimpulkan bahwa pengaruh kegunaan, keuntungan, dan keamanan berpengaruh secara serempak terhadap minat menggunakan mobile banking pada BNI cabang Palu, sehingga hipotesis didukung.

\section{KESIMPULAN DAN SARAN}

\section{Kesimpulan}

Berdasarkan hasil dan pembahasan penelitian maka berikut beberapa kesimpulan yang menyangkut penelitian ini dengan judul "Pengaruh Persepsi Kegunaan, Persepsi Keuntungan, dan Persepsi Keamanan Terhadap Minat Nasabah Bank BNI dalam Menggunakan Mobile Banking Pada BNI Cabang Palu", adalah sebagai berikut:

1. Persepsi kegunaan, persepsi keuntungan dan persepsi keamanan secara serempak berpengaruh signifikan terhadap minat nasabah Bank BNI dalam menggunakan mobile banking pada BNI cabang Palu.

2. Persepsi kegunaan mempunyai pengaruh signifikan terhadap minat nasabah Bank BNI dalam menggunaan mobile banking pada BNI cabang Palu.

3. Persepsi keuntungan mempunyai pengaruh signifikan terhadap minat nasabah Bank BNI dalam menggunakan mobile banking pada BNI cabang Palu.

4. Persepsi keamanan mempunyai pengaruh signifikan terhadap minat nasabah Bank BNI dalam menggunakan mobile banking pada BNI cabang Palu.

\section{Saran}

Adapun saran-saran berdasarkan kesimpulan di atas ataupun saran-saran lainnya yang dapat penulis berikan adalah:

1. Bank BNI diharapkan harus terus mengontrol dan mengevaluasi variabel-variabel yang terbukti memberikan pengaruh yang signifikan terhadap minat nasabah dalam menggunakan mobile banking, agar terjadi peningkatan baik dari segi pengguna mobile banking dan efektivitas perusahaan maupun dari segi keuntungan perusahaan.

2. Pegawai Bank BNI harus lebih giat lagi untuk memperkenalkan produk mobile banking kepada masyarakat agar mereka lebih mengetahui apa saja kegunaan, keuntungan, serta keamanan dari mobile banking tersebut sehingga dapat meningkatkan minat dalam penggunaan mobile banking.

3. Diharapkan peneliti selanjutnya untuk mencari, menambahkan, atau bahkan mengkombinasikan variabel-variabel dalam minat nasabah dalam menggunakan mobile banking, agar hasil penelitiannya memberikan kontribusi yang bermakna pada pihak-pihak yang berkepentingan. 


\section{REFERENSI}

Amanullah, B 2014. Pengaruh Persepsi Manfaat, Kemudahan Penggunaan, dan Kepercayaan Terhadap Sikap Positif BCA (Survey Pada Nasabah Bank BCA Semarang). Skripsi Universitas Diponegoro.

Davis, F.D, 1989. Perceived Usefulness, Perceived Ease of Use, and User Acceptance of Information technology. MIS Quarterly. Vol.13 No.3.h. 318-319.

Ellitan dan Anatan, 2015. Sistem Informasi Manajemen. Alfabeta, Bandung.

Ferdinand A, 2011. Metode Penelitian Manajemen. Badan Penerbit Universitas Diponegoro, Semarang.

Ghozali, 2005. Aplikasi Analisis Multivariate dengan program SPSS. Badan Penerbit Universitas Diponegoro, Semarang.

Jogiyanto, 2007. Sistem Informasi Keperilakuan. Yogyakarta.

Kotler Philip, 2001. Manajemen Pemasaran di Indonesia : Analisis, Perencanaan, Implementasi dan Pengendalian. Salemba Empat, Jakarta.

Kotler \& Keller, 2009. Manajemen Pemasaran. Jilid I Edisi ke 13, Erlangga, Jakarta.

Malhotra, N.K. 2006, Riset Pemasaran: Pendekatan Terapan. PT.Indeks, Jakarta.

Simamora B, 2005. Analisis Multivariat Pemasaran. Penerbit PT Gramedia Pustaka Utama, Jakarta.

Slameto, 2010. Belajar dan Faktor-Faktor yang Mempengaruhinya. PT Rineka Cipta, Jakarta.

Stanton, William J, 2001. Prinsip Pemasaran. Penerbit Erlangga, Jakarta.

Sugiyono, 2009. Metode Penelitian Kuantitatif dan R\&D. Alfabeta, Bandung.

Sunyoto, 2012. Manajemen Pemasaran. Buku Seru, Yogyakarta

Umar, H. 2010. Riset Pemasaran dan Perilaku Konsumen. PT. Gramedia Pustaka Utama, Jakarta.

Widiyanto, 2008. Metodologi Penelitian. Hal.19 BP Universitas Diponegoro, Semarang

http://www.bni.co.id. Diakses pada tangga 14 April 2017 pukul 16.13 WITA.

https://id.wikipedia.org/wiki/Keamanan. Diakses pada tanggal 15 November 2017 pukul 11.40 WITA. 